\title{
Combination of amlodipine and atorvastatin synergistically reduces leukocyte recruitment to mechanically injured mouse femoral artery
}

\author{
Sumihiko Hagita $^{1,2}$, Mizuko Osaka ${ }^{1}$, Kentaro Shimokado ${ }^{2}$ and Masayuki Yoshida ${ }^{1}$
}

Recent studies have demonstrated a potential synergistic effect of the combination of amlodipine with atorvastatin to reduce acute inflammation. The intraluminal wire injury of the mouse femoral artery induced significant leukocyte recruitment to the injured area and oxidative stress within $24 \mathrm{~h}$. Administration of low-dose amlodipine $\left(0.5 \mathrm{mg} \mathrm{kg}^{-1}\right.$ per day) or atorvastatin ( $1 \mathrm{mg} \mathrm{kg}^{-1}$ per day) alone for 7 days failed to modulate leukocyte adhesion, whereas their co-administration for 7 days significantly inhibited leukocyte adhesion. Moreover, flow cytometric analysis showed that injury-induced oxidative stress and CD11b expression in three leukocyte fractions were elevated after injury and then reduced after the co-administration. Next, adoptive transfer of mononuclear cells (MNCs) was performed and MNCs were harvested from mice after wire injury exhibited adhesion to the recipient injured artery. Furthermore, the co-administration of low-dose atorvastatin and amlodipine to MNCs or the vasculature reduced the recruitment of MNCs to the injured artery. Our findings indicate that amlodipine and atorvastatin synergistically inhibit vascular inflammation. The underlying mechanisms of their effect involve, at least in part, stabilizing oxidative stress at the point of injury, suggesting the clinical efficacy of this drug combination for the treatment of vascular diseases.

Hypertension Research (2011) 34, 450-455; doi:10.1038/hr.2010.254; published online 27 January 2011

Keywords: calcium channel blocker; cell adhesion; intravital microscopy; statin

\section{INTRODUCTION}

Recent clinical studies have emphasized the importance and efficacy of global management of multiple risk factors such as dyslipidemia and hypertension. ${ }^{1-3}$ Co-treatment with the HMG-CoA reductase inhibitors (statins) and calcium channel blockers (CCBs) significantly contributed to the reduction of cardiovascular events. ${ }^{4-9}$ The AngloScandinavian Cardiac Outcomes Trial-Lipid Lowering Arm recently documented a striking efficacy of adding atorvastatin to hypertensive patients without obvious dyslipidemia. ${ }^{10}$ Recent subanalysis of that study further revealed a large relative reduction in cardiovascular events in patients receiving amlodipine plus atorvastatin. ${ }^{11}$ To explore the biological backgrounds related to these clinical outcomes, we studied the effects of these compounds on vascular inflammation.

Accumulating evidence suggests that inflammation, manifested by leukocyte recruitment to the vasculature, has an important role in atherosclerosis. ${ }^{12,13}$ We previously reported that statin or CCB administration reduced leukocyte recruitment to cytokine-activated vascular endothelium under physiological conditions in vitro. ${ }^{14-16}$ However, the combined effect of a statin with a CCB and their efficacy in vivo is not fully understood.
As previously reported, the effects of oxidative stress on leukocytes and vasculature have a major role in inflammation. In fact, we reported the importance of oxidative stress with leukocytes in acute phase adhesion after vascular injury. In the present study, we compared the effects of a combination of a statin, atorvastatin, and a CCB, amlodipine, on inflammatory vascular injury, by focusing on their effects on leukocyte adhesion and underlying mechanisms.

\section{METHODS}

Reagents

Atorvastatin calcium and amlodipine besylate were kindly provided by Pfizer Japan, Tokyo, Japan.

\section{Animals}

Male C57BL/6J mice (7 weeks of age) were obtained from Oriental Yeast (Tokyo, Japan). They were fed standard chow (Clea Japan, Tokyo, Japan), with food and water provided ad libitum. The experiments were approved by the ethical committee for animal experimentation of Tokyo Medical and Dental University, Tokyo, Japan. Atorvastatin $\left(1 \mathrm{mg} \mathrm{kg}^{-1}\right.$ per day), amlodipine $\left(0.5 \mathrm{mg} \mathrm{kg}^{-1}\right.$ per day), those in combination, or the vehicle alone (methylcellulose)

${ }^{1}$ Life Science and Bioethics Research Center, Tokyo Medical and Dental University, Tokyo, Japan and ${ }^{2}$ Department of Vascular Medicine, Tokyo Medical and Dental University, Tokyo, Japan

Correspondence: Professor M Yoshida, Tokyo Medical and Dental University, Life Science and Bioethics Research Center, 1-5-45, Yushima D9, Bunkyo-ku, Tokyo 113-8510, Japan. E-mail: masa.vasc@tmd.ac.jp

Received 21 July 2010; revised 28 September 2010; accepted 2 October 2010; published online 27 January 2011 
was administered orally for 7 days before wire injury. In some experiments, higher doses of atorvastatin $\left(10 \mathrm{mg} \mathrm{kg}^{-1}\right.$ per day) and amlodipine $\left(3 \mathrm{mg} \mathrm{kg}^{-1}\right.$ per day) were used. Systolic blood pressure and heart rate during the experiments were measured using a tail cuff with a noninvasive automatic sphygmomanometer (BP-98A, Softron, Tokyo, Japan).

Mechanical injury to the femoral artery was induced by insertion of a large wire $(0.38 \mathrm{~mm}$ in diameter, No. C-SF-1515, Cook, Bloomington, IN, USA), as previously described. ${ }^{17,18}$ Briefly, the femoral artery was exposed, and upstream and downstream areas of the arterial branch were clamped. Then, a guide wire was inserted into the femoral artery and removed from the vessel, followed by branch ligation. This procedure caused complete endothelial denudation. The operative time to perform the femoral injury ranged from 20 to $30 \mathrm{~min}$, and all mice survived until the time of microscopic examination.

\section{Intravital microscopy}

Intravital microscopic examinations of the injured femoral arteries were performed at $24 \mathrm{~h}$ after wire injury, as previously described. ${ }^{17,18}$ Briefly, the mice were anesthetized with pentobarbital and mechanically ventilated so as to maintain a normal acid-base balance. Rectal temperature was kept at 36.0$37.0^{\circ} \mathrm{C}$ with a heating pad and an infrared heat lamp. After injection of rhodamine $6 \mathrm{G}$ chloride (Invitrogen, Carlsbad, CA, USA; $0.3 \mathrm{mg} \mathrm{kg}^{-1}$ in $300 \mu \mathrm{l}$ of phosphate buffered saline $(-)$ ) into the right femoral vein, the injured femoral artery was visualized with a fluorescent microscope (BX51WI, Olympus, Tokyo, Japan) equipped with a water immersion objective $(\times 20)$. Epifluorescence was illuminated by a $100-\mathrm{W}$ fluorescent lamp source and images were directly captured to a PC via a CCD camera (CoolSnap HQ, Olympus). Each experimental group consisted of at least eight mice. Serum samples were obtained, and the injured femoral arteries were harvested, then immediately frozen and preserved at $-20^{\circ} \mathrm{C}$ until the time of analysis.

\section{Image analysis}

Adhesion of leukocytes was clearly visualized on the anterior half of the vessels facing the objective. All images were analyzed using an image analysis program (MetaMorph; Molecular Devices, Sunnyvale, CA, USA) in accordance with the manufacturer's protocol, as previously described. ${ }^{17,18}$ Briefly, the number of adherent cells during the 1-min recording period was counted in a region of interest, a $100-\mu \mathrm{m} \times 100-\mu \mathrm{m}$ rectangle segment of the vessel, and expressed as the number of adherent cells per $10^{4} \mu \mathrm{m}^{2}$ on the vessel surface.

\section{Detection of local oxidative stress}

To detect oxidative stress in the injured femoral arteries in vivo, we conducted intravital microscopy after intravenous injection of dihydroethidium (DHE), a fluorescent dye used to quantify oxidative stress production. Intravital microscopic analysis was performed $5 \mathrm{~min}$ after injection of DHE, and DHEassociated fluorescence of cells and injured vasculature were observed under a fluorescent microscope. The magnitude of oxidative stress was estimated as the ratio of the fluorescence-positive areas to the captured images.

\section{Intravenous injection of externally labeled MNCs}

Mononuclear cells (MNCs) were isolated from peripheral blood taken from three mice with wire injuries by gradient centrifugation using an LSM (Histopaque-1083, Sigma Aldrich Corp., St Louis, MO, USA). They were labeled with rhodamine $6 \mathrm{G}$ chloride and then $5 \times 10^{5}$ cells were injected intravenously into other mice for intravital microscopy observation. In some experiments, recipient or donor mice were treated with atorvastatin, amlodipine or those in combination.

\section{Flow cytometry}

For the detection of cell surface CD11b and intracellular oxidative stress, white blood cells were prepared by hemolyzing whole blood (about $2 \mathrm{ml}$ ) from two mice in each group. First, the cells were incubated with anti-mouse CD11b (1:10, MCA74, AbD Serotec, Oxford, UK) for $45 \mathrm{~min}$ on ice, followed by a FITC-conjugated secondary antibody (1:20, R\&D Systems, Minneapolis, MN, USA) for $45 \mathrm{~min}$ on ice. Next, they were incubated with DHE (1:250) for $25 \mathrm{~min}$. After three washings, fluorescence activity was detected from fractions of 5000 cells using a FACS caliber at $480 \mathrm{~nm}$ (CD11b) or $580 \mathrm{~nm}$ (DHE), and the data were analyzed by CellQuest software (Becton Dickinson, Franklin Lakes, NJ, USA). When fluorescence activity was detected, data were obtained from three cell subsets (lymphocytes, granulocytes and monocytes) using gating definition, as previously described. ${ }^{19-21}$

\section{Immunoblotting}

Tissue lysates were prepared from the injured arteries for immunoblotting analysis. Identical amounts of protein were separated by SDS-PAGE and blotted onto nitrocellulose membranes. Nicotinamide adenine dinucleotide phosphate $(\mathrm{NAD}(\mathrm{P}) \mathrm{H})$ oxidase components, $\mathrm{p} 47^{\mathrm{phox}}$ and $\mathrm{p} 67^{\text {phox }}$, were analyzed using their respective mouse polyclonal antibodies (Santa Cruz Biotechnology, Inc., Santa Cruz, CA, USA), followed by a horseradish peroxidaselabeled secondary antibody.

\section{Statistical analysis}

Data are expressed as the mean value \pm s.e.m. One-way analysis of variance with a Tukey's post hoc test or two-tailed unpaired $t$-test was used to estimate statistical significance, with a value of $P<0.05$ considered to be statistically significant.

\section{RESULTS}

Atorvastatin and amlodipine reduced leukocyte adhesion to injured femoral arteries in vivo

As we demonstrated previously, luminal wire insertion induced significant leukocyte adhesion to the femoral artery at $24 \mathrm{~h}$ after injury in the vehicle alone group (Figure 1b). In contrast, treatment with higher doses of amlodipine $\left(3 \mathrm{mg} \mathrm{kg}^{-1}\right.$ per day) or atorvastatin $\left(10 \mathrm{mg} \mathrm{kg}^{-1}\right.$ per day) reduced leukocyte adhesion (Supplementary Figure 1), whereas lower doses of amlodipine $\left(0.5 \mathrm{mg} \mathrm{kg}^{-1}\right.$ per day; Figure 1c) or atorvastatin $\left(1 \mathrm{mg} \mathrm{kg}^{-1}\right.$ per day; Figure 1d) failed to inhibit leukocyte adhesion. However, combined lower doses of amlodipine and atorvastatin effectively inhibited leukocyte adhesion to the injured artery, as shown by the representative microphotographs presented in Figure 1e. Systolic blood pressure, heart rate and serum total cholesterol level were not significantly changed during the experiments in any of the mice (Supplementary Table 1).

\section{Integrin expression in leukocytes after vascular injury}

To elucidate the molecular mechanism of the synergistic effects of amlodipine and atorvastatin, we evaluated CD11b expression after injury by flow cytometry (Figure 2). The wire injury increased CD11b expression in monocytes and granulocytes but not in lymphocytes. Atorvastatin alone did not dramatically affect CD11b expression in monocytes and granulocytes, whereas amlodipine alone moderately reduced that expression in monocytes and granulocytes. Moreover, the combination of atorvastatin and amlodipine potently reduced $\mathrm{CD} 11 \mathrm{~b}$ expression in monocytes and granulocytes (Supplementary Figure 2).

\section{Role of oxidative stress in leukocyte recruitment after vascular injury}

Previously, we demonstrated that local oxidative stress was increased after mechanical injury to the artery. ${ }^{18}$ To examine whether atorvastatin and amlodipine have anti-oxidative properties, we monitored oxidative stress in the injured arteries using DHE, a fluorescence probe for superoxide, to visualize oxidative stress in situ. As shown in Figure 3a, oxidative stress in the vasculature was significantly increased by vascular injury, which was subsequently reduced by low-dose atorvastatin or amlodipine. However, the two in combination exerted a much greater reduction of DHE-associated oxidative stress in the vasculature.

We also measured oxidative stress in monocytes and granulocytes. As shown in Figure 3b, oxidative stress in monocytes and granulocytes was significantly increased by vascular injury, which was subsequently 

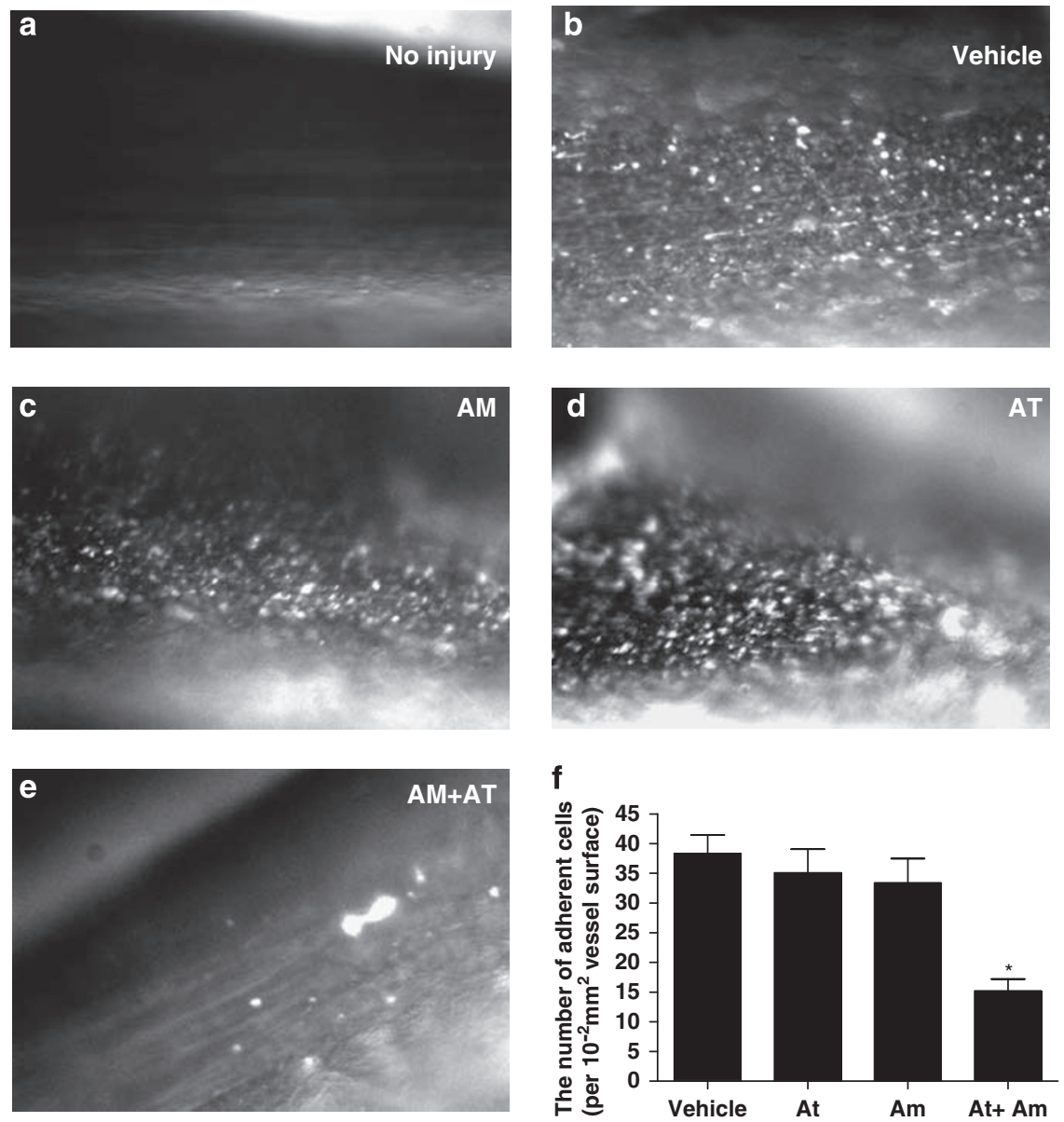

Figure 1 Leukocyte adhesive interactions in the mouse injured arteries. (a-e) Microphotographs of leukocyte recruitment to femoral arteries in mice at $24 \mathrm{~h}$ after wire injury. Representative snapshots of the mouse femoral artery without mechanical injury (a: No injury) and those with injury treated with vehicle (b: Vehicle), $1 \mathrm{mg} \mathrm{kg}^{-1}$ per day of atorvastatin (c: At), $0.5 \mathrm{mg} \mathrm{kg}^{-1}$ per day of amlodipine (d: Am) or their combination (e: At+Am) for 7 days. (f) The numbers of adherent cells in all groups were quantitated, as described in Methods. Values are the mean \pm s.e.m. of 10 mice in each group. ${ }^{*} P<0.01$ vs. vehicle treatment group.

reduced by low-dose atorvastatin or amlodipine. However, those in combination exerted a much greater reduction of DHE-associated oxidative stress.

\section{Adoptive transfer of MNCs}

To define the focus of oxidative stress and inflammation, we performed an adoptive transfer of peripheral MNCs. When MNCs taken from injured mice were administered intravenously into recipient injured mice, we observed significant leukocyte adhesion in the injury areas of the recipient mice (Veh $>$ Veh), as shown in Figure 4. Next, MNCs were taken from mice treated with atrovastatin (At) and amlodipine (Am) for 7 days, and transferred to injured mice without treatment $(A t+A m>V e h)$ or vice versa $(\mathrm{Veh}>>A t+A m)$. The number of MNC adhesions in those mice was significantly reduced as compared with the control under both the conditions.

Effect of combination treatment with atorvastatin and amlodipine on expression of $\mathrm{NAD}(\mathrm{P}) \mathrm{H}$ oxidase component in mechanically injured arteries

To confirm the effects of atorvastatin, amlodipine and those in combination on the expression of $\mathrm{NAD}(\mathrm{P}) \mathrm{H}$ oxidase subunits in the injured arteries, we performed immunoblotting analysis using the $\mathrm{p} 47^{\text {phox }}$ and $\mathrm{p} 67^{\text {phox }}$ antibodies. As shown in Figure 5, the expressions of both components were significantly increased by vascular injury, while the expression level of $\mathrm{p} 47^{\text {phox }}$ was moderately decreased by lowdose treatment with atorvastatin alone, but not by that with amlodipine. In contrast, p67 $67^{\text {phox }}$ was reduced by low-dose treatment with both drugs, while those in combination significantly reduced the expressions of these subunits in the injured vasculature.

\section{DISCUSSION}

Leukocyte adhesion, considered to be one of the crucial mechanisms involved in vascular inflammation, is a multi-step complex cascade controlled by various factors, including adhesion molecules and soluble factors. We recently developed a novel intravital microscopic system to directly monitor leukocyte recruitment in athero-prone arteries in vivo. ${ }^{17,18}$ Using our technique, we have found that oxidative stress has an important role in leukocyte recruitment after luminal injury and documented the anti-inflammatory potential of compounds related to cardiovascular diseases. ${ }^{18}$

In the present study, we examined the effects of atorvastatin and amlodipine on the recruitment of leukocytes to the site of vascular injury. Low doses of atorvastatin or amlodipine failed to inhibit leukocyte adhesion; however, the combination of both at low doses significantly reduced leukocyte recruitment to the injured artery. With adequate doses, both amlodipine alone and atorvastatin alone were 
$\mathrm{Gr}$
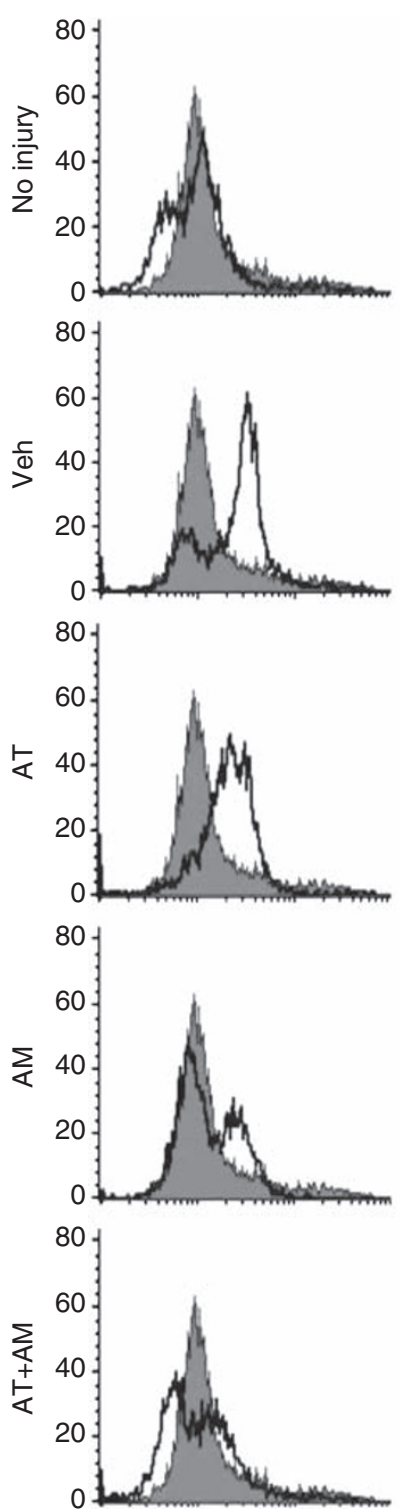

Mo
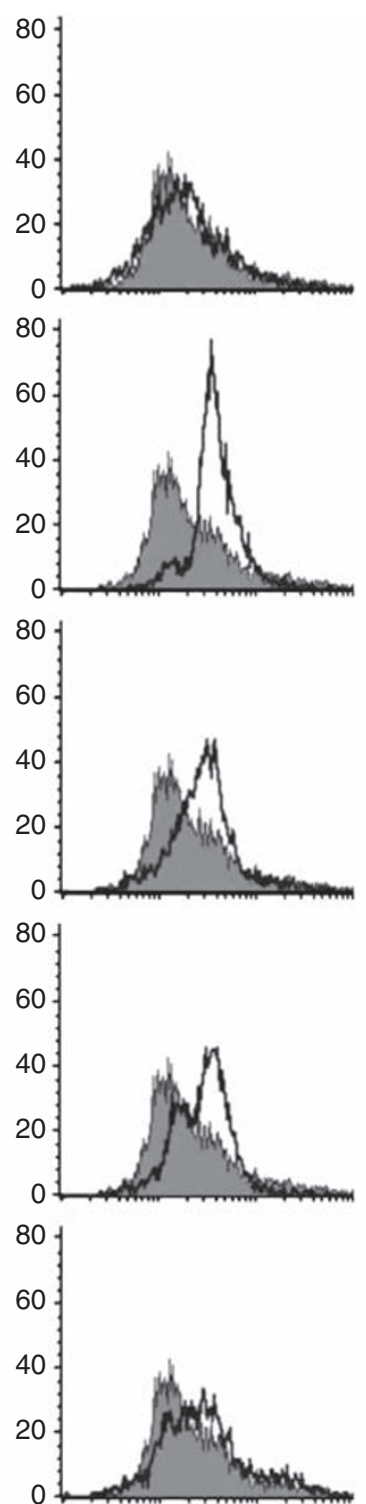

Ly
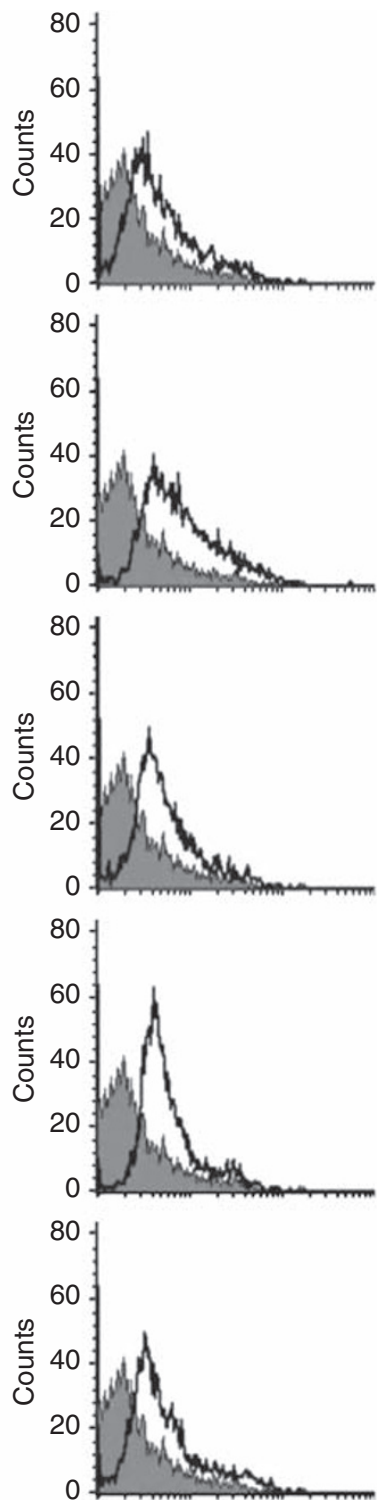

Figure 2 The expression level of cell surface CD11b in leukocyte subpopulations (granulocyte (Gr), monocyte (Mo) and lymphocyte (Ly)). CD11b expression was measured by flow cytometry using anti-CD11b monoclonal antibody as described in Methods. Gray area represents IgG control and CD11b expression is expressed as a solid line. Data are representative of five independent experiments.

shown to be able to reduce atherosclerosis in animal and human studies. ${ }^{22-24}$ Although we previously found anti-inflammatory roles for amlodipine and atorvastatin in vitro, the present study is the first known to monitor their effects on vascular injury in vivo. Our observations revealed the efficacy of amlodipine and atorvastatin in combination for stabilizing vascular inflammation.

The mechanisms by which these compounds reduce leukocyte adhesion involve downregulation of CD11b integrin and oxidative stress in leukocytes. As we previously reported, the level of CD11b expression on the surface of leukocytes is closely correlated with their adhesion to injured vessels. ${ }^{17,18}$ Therefore, the reduction of CD11b expression by amlodipine is a critically important mechanism for its anti-adhesive effects in vivo.

As demonstrated in our previous study, amlodipine inhibits monocyte adhesion in vitro by reducing protein kinase $\mathrm{C}$ activation.
Therefore, we speculated that similar intracellular mechanisms may be operative in the current findings. Oxidative stress directly induces leukocyte adhesion during mechanical injury, ${ }^{18}$ while others have reported an association between $\mathrm{CD} 11 \mathrm{~b}$ and Nox2, a component of $\mathrm{NAD}(\mathrm{P}) \mathrm{H}$ oxidase subunits, in vascular injury. ${ }^{25}$ Also, a reduction in $\mathrm{NAD}(\mathrm{P}) \mathrm{H}$ oxidase-mediated oxidative stress was found to inhibit $\mathrm{CD} 11 \mathrm{~b}$ expression in monocytes and neutrophils, as well as their firm adhesion to the vasculature. ${ }^{26,27}$ Thus, the anti-oxidative properties of amlodipine and atrovastatin may have a central role in the reduction of leukocyte recruitment observed in the present study.

As demonstrated in our adoptive transfer experiment, combination treatment reduced adhesive properties of the injured vasculature, as well as those of circulating leukocytes. Moreover, we found that the major $\mathrm{NAD}(\mathrm{P}) \mathrm{H}$ oxidase components $\mathrm{p} 47^{\text {phox }}$ and $\mathrm{p} 67^{\text {phox }}$ were significantly activated by mechanical injury, and then reduced by 


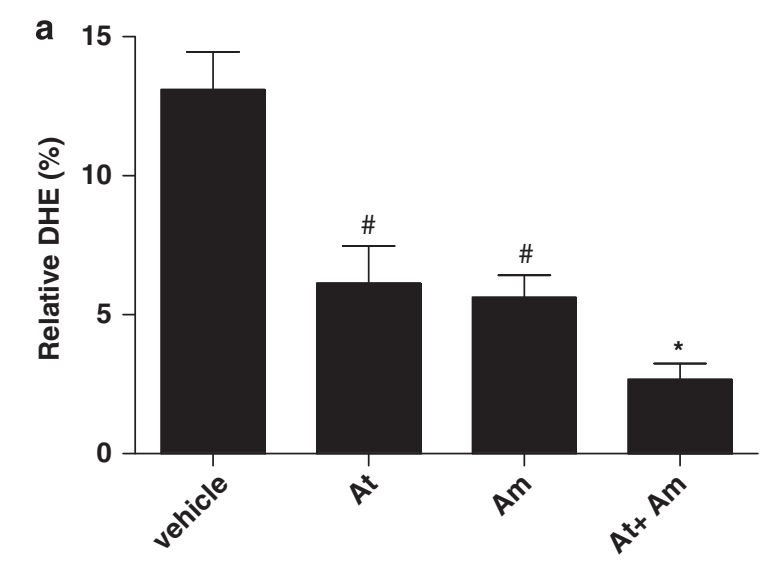

b
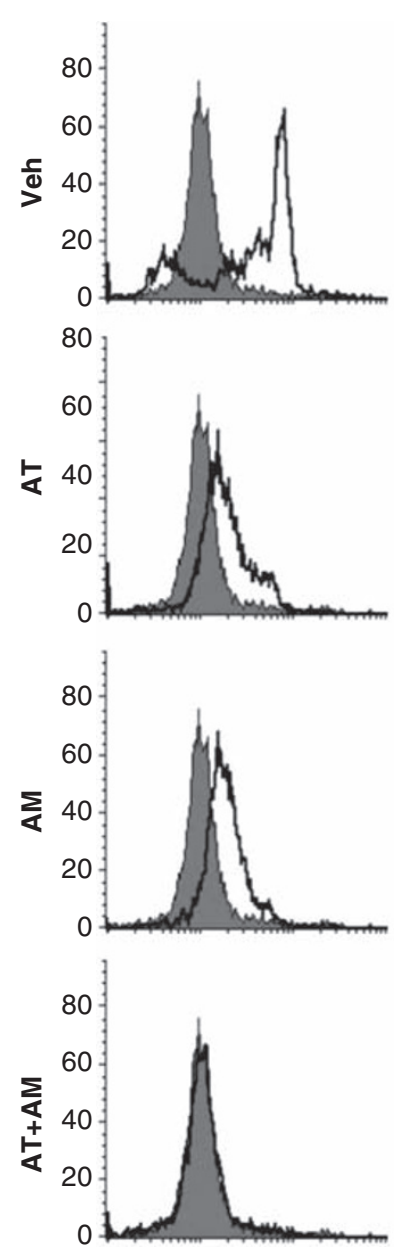

Mo
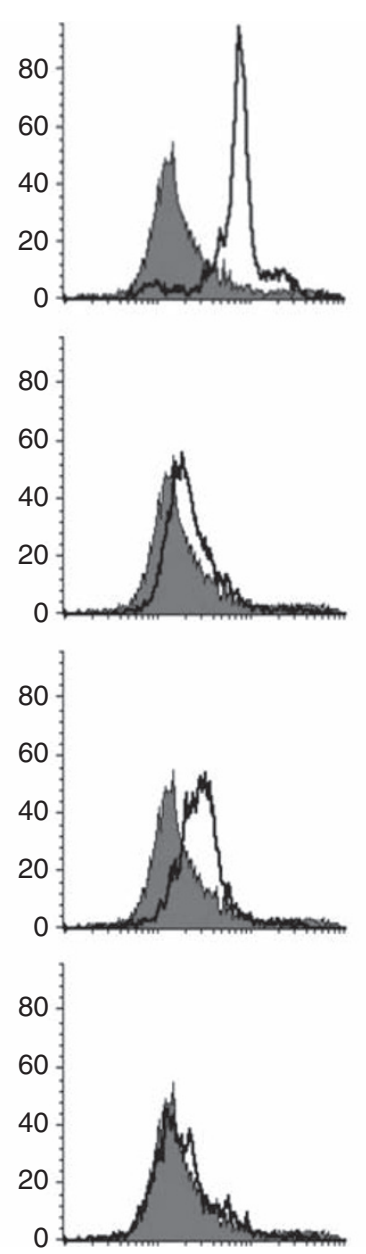

Ly
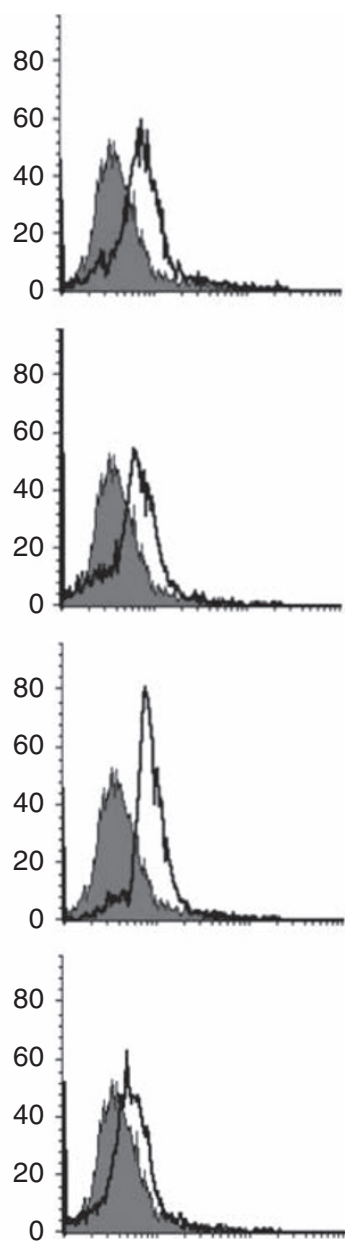

Figure 3 Measurement of oxidative stress in vessel wall and leukocytes. (a) Oxidative stress in the inured artery was visualized by dihydroethidium (DHE) as described in the Methods. The relative measurement of the DHE-positive area to the observed vessel wall area was quantified in vehicle-treated (Vehicle), atorvastatin-treated (At), amlodipine-treated $(\mathrm{Am})$ and combination of these drugs treated (At+Am) mice at $24 \mathrm{~h}$ after injury. Values are the mean $\pm \mathrm{s}$.e.m. (four mice in each group). ${ }^{*} P<0.01,{ }^{\#} P<0.05$ vs. vehicle treatment group at each time point. (b) DHE-associated fluorescence activity was measured in leukocyte subpopulations; granulocytes (Gr), monocytes (Mo) and lymphocytes (Ly) as described in Methods. Gray area represents DHE intensity of no injury group and each solid line represents intensity of each group. Data are representative of five independent experiments.

combined treatment with atorvastatin and amlodipine in the injured vasculature. This data provides good agreement with our previous observation using apocynin to block mechanical injury-induced leukocyte recruitment. ${ }^{18}$ As we previously reported, the intravenous injection of P-selection antibody significantly reduced leukocyte adhesion after mechanical injury. ${ }^{17}$ We also documented the upregulation of serum IL-6 after mechanical injury. ${ }^{17}$ These data strongly suggest the importance of these molecules in this phenomenon.

In conclusion, the combination of a statin, atorvastatin and a CCB, amlodipine, was shown to synergistically reduce inflammatory cas- 


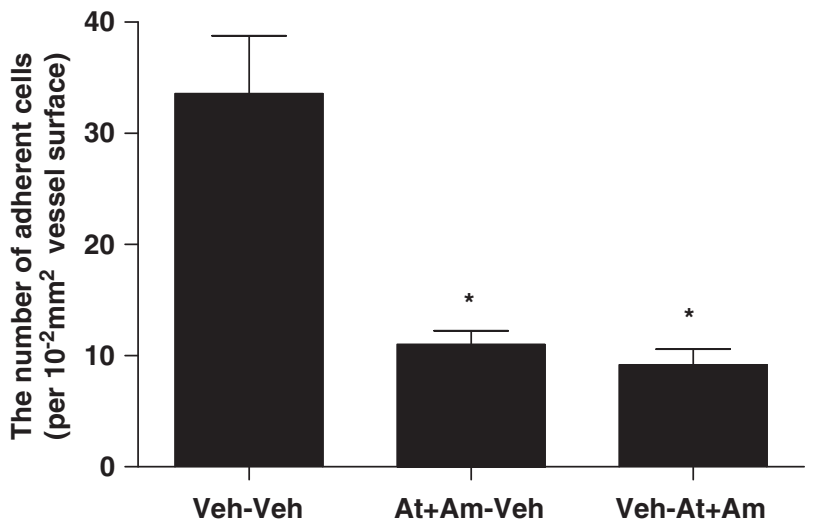

Figure 4 Adhesion of exogenous mononuclear cells (MNCs) to the injured artery was examined using intravital microscopic analysis at $24 \mathrm{~h}$ after injury. The experimental conditions are as follows: MNCs from vehicletreated mice transferred to those treated with vehicle (Veh-Veh), MNCs from atorvastatin and amlodipine-treated mice transferred to those with vehicle (At+Am-Veh), MNCs from vehicle-treated mice transferred to those treated with combination of atorvastatin and amlodipine (Veh-At+Am) ${ }^{*} P<0.05$ vs. Veh-Veh group.

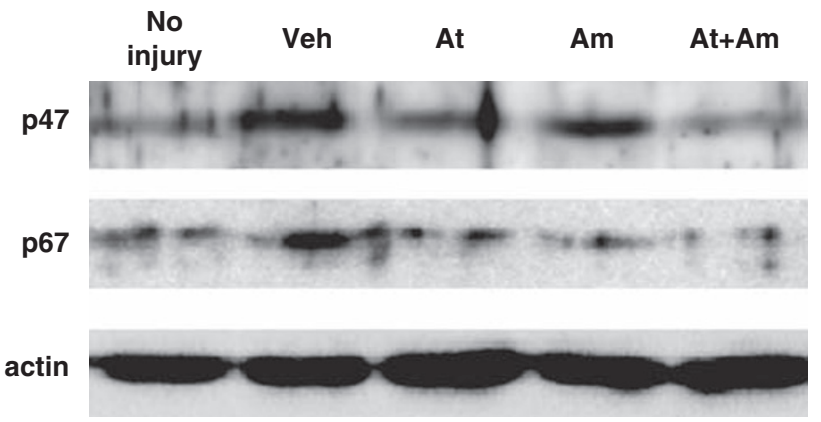

Figure 5 Effects of combination treatment of atorvastatin and amlodipine on the expression of nicotinamide adenine dinucleotide phosphate oxidase subunits in the injured artery. Oxidative stress marker, $\mathrm{NAD}(\mathrm{P}) \mathrm{H}$ oxidase subunits, p47phox and $6^{\text {phox }}$ in the inured artery of vehicle-treated (Veh), atorvastatin-treated (At), amlodipine-treated (Am) and combination of these drugs treated $(A t+A m)$ mice at $24 \mathrm{~h}$ after injury were evaluated by western blotting analysis as described in Methods.

cades during vascular injury in vivo. The underlying mechanisms seem to involve reduction of $\mathrm{CD} 11 \mathrm{~b}$ expression and oxidative stress. Our data findings support the clinical efficacy of the present combination therapy.

\section{CONFLICT OF INTEREST}

The authors declare no conflict of interest.

1 Schiffrin E, Lipman M, Mann J. Chronic kidney disease: effects on the cardiovascular system. Circulation 2007; 116: 85-97.

2 Lamon B, Hajjar D. Inflammation at the molecular interface of atherogenesis: an anthropological journey. Am J Pathol 2008; 173: 1253-1264.

3 Sowers J, Epstein M, Frohlich E. Diabetes, hypertension, and cardiovascular disease: an update. Hypertension 2001; 37: 1053-1059.

4 Trion A, de Maat M, Jukema W, Maas A, Offerman E, Havekes L, Szalai A, van der Laarse A, Princen $\mathrm{H}$, Emeis J. Anti-atherosclerotic effect of amlodipine, alone and in combination with atorvastatin, in APOE*3-Leiden/HCRP transgenic mice. J Cardiovasc Pharmacol 2006; 47: 89-95.
5 Rossoni G, Manfredi B, Civelli M, Berti F, Razzetti R. Combined simvastatin-manidipine protect against ischemia-reperfusion injury in isolated hearts from normocholesterolemic rats. Eur J Pharmacol 2008; 587: 224-230.

6 Martín-Ventura J, Muñoz-Garcia B, Blanco-Colio L, Martín-Conejero A, Madrigal-Matute J, Vega M, Ortega L, Serrano J, Egido J. Treatment with amlodipine and atorvastatin has additive effect on blood and plaque inflammation in hypertensive patients with carotid atherosclerosis. Kidney Int Suppl 2008; 74: S71-S74.

7 Mason R, Kubant R, Heeba G, Jacob R, Day C, Medlin Y, Funovics P, Malinski T. Synergistic effect of amlodipine and atorvastatin in reversing LDL-induced endothelial dysfunction. Pharm Res 2008; 25: 1798-1806.

8 Takayama M, Matsubara M, Arakawa E, Takada C, Ina Y, Hasegawa K, Yao K. Comparison of the antiatherosclerotic effects of dihydropyridine calcium channel blocker and HMG-CoA reductase inhibitor on hypercholesterolemic rabbits. Vascul Pharmacol 2007; 46: 302-308.

9 Devabhaktuni M, Bangalore S. Fixed combination of amlodipine and atorvastatin in cardiovascular risk management: patient perspectives. Vasc Health Risk Manag 2009; 5: 377-387.

10 Sever P, Dahlöf B, Poulter N, Wedel H, Beevers G, Caulfield M, Collins R, Kjeldsen S, Kristinsson A, Mclnnes G, Mehlsen J, Nieminen M, O'Brien E, Ostergren J, investigators A. Prevention of coronary and stroke events with atorvastatin in hypertensive patients who have average or lower-than-average cholesterol concentrations, in the anglo-Scandinavian cardiac outcomes trial-lipid lowering arm (ASCOT-LLA): a multicentre randomised controlled trial. Lancet 2003; 361: 1149-1158.

11 Sever P, Dahlöf B, Poulter N, Wedel H, Beevers G, Caulfield M, Collins R, Kjeldsen S, Kristinsson A, McInnes G, Mehlsen J, Nieminem M, O'Brien E, Ostergren J, Members ASC. Potential synergy between lipid-lowering and blood-pressure-lowering in the anglo-Scandinavian cardiac outcomes trial. Eur Heart J 2006; 27: 2982-2988.

12 Gawaz M, Langer $\mathrm{H}$, May A. Platelets in inflammation and atherogenesis. J Clin Invest 2005; 115: 3378-3384.

13 Rao R, Yang L, Garcia-Cardena G, Luscinskas F. Endothelial-dependent mechanisms of leukocyte recruitment to the vascular wall. Circ Res 2007; 101: 234-247.

14 Kawakami A, Tanaka A, Nakajima K, Shimokado K, Yoshida M. Atorvastatin attenuates remnant lipoprotein-induced monocyte adhesion to vascular endothelium under flow conditions. Circ Res 2002; 91: 263-271.

15 Yu T, Morita I, Shimokado K, Iwai T, Yoshida M. Amlodipine modulates THP-1 cell adhesion to vascular endothelium via inhibition of protein kinase $C$ signal transduction. Hypertension 2003; 42: 329-334.

16 Yoshida M, Sawada T, Ishii H, Gerszten R, Rosenzweig A, Gimbrone MJ, Yasukochi Y, Numano F. HMG-CoA reductase inhibitor modulates monocyte-endothelial cell interaction under physiological flow conditions in vitro: involvement of rho GTPase-dependent mechanism. Arterioscler Thromb Vasc Biol 2001; 21: 1165-1171.

17 Osaka M, Hagita S, Haraguchi M, Kajimura M, Suematsu M, Yoshida M. Real-time imaging of mechanically injured femoral artery in mice reveals a biphasic pattern of leukocyte accumulation. Am J Physiol Heart Circ Physiol 2007; 292: H1876-H1882.

18 Hagita S, Osaka M, Shimokado K, Yoshida M. Oxidative stress in mononuclear cells plays a dominant role in their adhesion to mouse femoral artery after injury. Hypertension 2008; 51: 797-802.

19 Matsuyama N, Kojima Y, Hirayama F, Yasui K, Taniue A, Fukumori Y, Yoshimura K, Tabata N, Sakata N, Tani Y, Shibata H. Simultaneous five cell-lineage flow cytometric analysis system for detection of leucocyte antibodies. Transfus Med 2006; 16: 111-118.

20 Lazarus A, Ellis J, Blanchette V, Freedman J, Sheng-Tanner X. Permeabilization and fixation conditions for intracellular flow cytometric detection of the T-cell receptor zeta chain and other intracellular proteins in lymphocyte subpopulations. Cytometry 1998; 32: 206-213.

21 Linssen J, Aderhold S, Nierhaus A, Frings D, Kaltschmidt C, Zänker K. Automation and validation of a rapid method to assess neutrophil and monocyte activation by routine fluorescence flow cytometry in vitro. Cytometry B Clin Cytom 2008; 74: 295-309.

22 Nakano K, Egashira K, Ohtani K, Gang Z, Iwata E, Miyagawa M, Sunagawa K. Azelnidipine has anti-atherosclerotic effects independent of its blood pressure-lowering actions in monkeys and mice. Atherosclerosis 2008; 196: 172-179.

23 Kyselovic J, Martinka P, Batova Z, Gazova A, Godfraind T. Calcium channel blocker inhibits western-type diet-evoked atherosclerosis development in ApoE-deficient mice. J Pharmacol Exp Ther 2005; 315: 320-328.

24 Yasa M, Kerry Z, Reel B, Yetik Anacak G, Ertuna E, Ozer A. The effects of calcium channel blockers are not related to their chemical structure in the collar model of the rabbit. J Int Med Res 2007; 35: 59-71.

25 Gao X, Zhu X, Fu J, Liu Q, Frey R, Malik A. Blockade of class IA phosphoinositide 3kinase in neutrophils prevents NADPH oxidase activation- and adhesion-dependent inflammation. J Biol Chem 2007; 282: 6116-6125.

26 Ryu J, Hong K, Maeng J, Kim J, Ko J, Park J, Lee K, Hong M, Park S, Kim Y, Han K. Overexpression of uncoupling protein 2 in THP1 monocytes inhibits beta2 integrinmediated firm adhesion and transendothelial migration. Arterioscler Thromb Vasc Biol 2004; 24: 864-870.

27 van Spriel A, Leusen J, van Egmond M, Dijkman H, Assmann K, Mayadas T, van de Winkel J. Mac-1 (CD11b/CD18) is essential for Fc receptor-mediated neutrophil cytotoxicity and immunologic synapse formation. Blood 2001; 97: 2478-2486. 